\title{
CIÊNCIA, TECNOLOGIA E SOCIEDADE: A RELEVÂNCIA DO ENFOQUE CTS PARA O CONTEXTO DO ENSINO MÉDIO
}

\section{Science, Technology and Society: the importance of the STS view to high school context}

\author{
Nilcéia Aparecida Maciel Pinheiro ${ }^{1}$ \\ Rosemari Monteiro Castilho Foggiatto Silveira ${ }^{2}$ \\ Walter Antonio Bazzo ${ }^{3}$
}

\begin{abstract}
Resumo: Ressalta-se a importância do enfoque Ciência, Tecnologia e Sociedade (CTS) perante os questionamentos críticos e reflexivos acerca do contexto científico-tecnológico e social e, em especial, sua relevância para o Ensino Médio. Os pressupostos do movimento CTS têm se ampliado em toda sociedade brasileira, principalmente na área educacional. Dentro da proposta da Lei de Diretrizes e Bases da Educação Nacional (LDB), configurada nos Parâmetros Curriculares Nacionais do Ensino Médio (PCNEMs), percebe-se a relevância de aproximar o aluno da interação com a ciência e a tecnologia em todas as dimensões da sociedade, oportunizando a ele uma concepção ampla e social do contexto científico-tecnológico.
\end{abstract}

Palavras-chave: CTS. Ensino Médio. Educação científica e tecnológica.

\begin{abstract}
We aim to highlight the importance of the STS view as a driving force of critical and reflexive questions about scientific, technological and social contexts, and also, to emphasize its relevance to High School. The STS movement has spread throughout our society and, specially, has gained more and more followers in the educational area. Inside the Guidelines Law of the National Education (LDB) proposal, designed in the National Curriculum Parameters for Secondary Education (PCNEMS), we noticed the importance of bringing the student closer to the interaction between science and technology in societal dimensions, considering their reciprocal relation, giving the students a wide and social conception of the scientific and technological context.
\end{abstract}

Key words: STS. High School. Scientific and technological education.

\footnotetext{
${ }^{1}$ Doutora em Educação Científica e Tecnológica; docente, Coordenação de Mecânica, Universidade Tecnológica Federal do Paraná (UTFPR), campus de Ponta Grossa. Ponta Grossa, PR. <nilceia@utfpr.edu.br>

${ }^{2}$ Doutoranda em Educação Científica e Tecnológica; docente, Coordenação de Mecânica, Universidade Tecnológica Federal do Paraná (UTFPR), campus de Ponta Grossa. Ponta Grossa, PR.

<rosemari@utfpr.edu.br>

${ }^{3}$ Doutor em Educação; docente, departamento de Engenharia Mecânica; Programa de Pós-Graduação em Educação Científica e Tecnológica, Universidade Federal de Santa Catarina (PPGECT/UFSC), Núcleo de Estudos e Pesquisas em Educação Tecnológica (NEPET). Florianópolis, SC. <wbazzo@emc.ufsc.br>
}

\footnotetext{
${ }^{1}$ Rua Herculano de Freitas, 20

Bairro São José - Ponta Grossa, PR

$84.070-200$
} 


\section{Introdução}

O desenvolvimento da ciência e da tecnologia tem acarretado diversas transformações na sociedade contemporânea, refletindo em mudanças nos níveis econômico, político e social. É comum considerarmos ciência e tecnologia motores do progresso que proporcionam não só desenvolvimento do saber humano, mas, também, uma evolução real para o homem. Vistas dessa forma, subentende-se que ambas trarão somente benefícios à humanidade. Porém, pode ser perigoso confiar excessivamente na ciência e na tecnologia, pois isso supõe um distanciamento de ambas em relação às questões com as quais se envolvem. As finalidades e interesses sociais, políticos, militares e econômicos que resultam no impulso dos usos de novas tecnologias implicam enormes riscos, porquanto o desenvolvimento científico-tecnológico e seus produtos não são independentes de seus interesses. Reforçando esses comentários, Bazzo (1998, p. 142) destaca que:

É inegável a contribuição que a ciência e a tecnologia trouxeram nos últimos anos. Porém, apesar desta constatação, não podemos confiar excessivamente nelas, tornando-nos cegos pelo conforto que nos proporcionam cotidianamente seus aparatos e dispositivos técnicos. Isso pode resultar perigoso porque, nesta anestesia que o deslumbramento da modernidade tecnológica nos oferece, podemos nos esquecer que a ciência e a tecnologia incorporam questões sociais, éticas e políticas.

Apesar de os meios de comunicação estarem disseminando os pontos preocupantes do desenvolvimento científico-tecnológico - como a produção de alimentos transgênicos, as possibilidades de problemas na construção de usinas nucleares, o tratamento ainda precário do lixo e outros - muitos cidadãos ainda têm dificuldades de perceber por quê se está comentando tais assuntos e em quê eles poderiam causar problemas a curto ou longo prazo. Mal sabem as pessoas que atrás de grandes promessas de avanços tecnológicos escondem-se lucros e interesses das classes dominantes. Essas que, muitas vezes, persuadindo as classes menos favorecidas, impõem seus interesses, fazendo com que as necessidades da grande maioria carente de benefícios não sejam amplamente satisfeitas.

Torna-se cada vez mais necessário que a população possa, além de ter acesso às informações sobre o desenvolvimento científico-tecnológico, ter também condições de avaliar e participar das decisões que venham a atingir o meio onde vive. É necessário que a sociedade, em geral, comece a questionar sobre os impactos da evolução e aplicação da ciência e tecnologia sobre seu entorno e consiga perceber que, muitas vezes, certas atitudes não atendem à maioria, mas, sim, aos interesses dominantes. A esse respeito, Bazzo (1998, p. 34) comenta: "o cidadão merece aprender a ler e entender - muito mais do que conceitos estanques - a ciência e a tecnologia, com suas implicações e conseqüências, para poder ser elemento participante nas decisões de ordem política e social que influenciarão o seu futuro e o dos seus filhos".

Precisamos constantemente considerar que somos atores sociais. Uns diretamente afetados pelas possíveis conseqüências da implantação de determinada tecnologia e que não podem evitar seu impacto; outros, os próprios consumidores de produtos tecnológicos, coletivo que pode protestar pela regulação e pelo uso das tecnologias; outros mais, público interessado, pessoas conscientes que vêem nas tecnologias um ataque a seus princípios ideológicos, como 
os ecologistas e várias ONGs; e, também, estudiosos de vários segmentos com condições de avaliar os riscos da área de conhecimento que dominam. Em suma, podemos ser capazes de avaliar e tomar decisões.

Cada cidadão tem seus valores e posturas sobre as questões científico-tecnológicas que, muitas vezes, vão ao encontro das demais. Por isso, uma adequada participação na tomada de decisões que envolve ciência e tecnologia deve passar por uma negociação. As pessoas precisam ter acesso à ciência e à tecnologia, não somente no sentido de entender e utilizar os artefatos e mentefatos ${ }^{4}$ como produtos ou conhecimentos, mas, também, opinar sobre o uso desses produtos, percebendo que não são neutros, nem definitivos, quem dirá absolutos. Bazzo (1998, p. 114) complementa essa idéia, comentando que:

É preciso que possamos retirar a ciência e a tecnologia de seus pedestais inabaláveis da investigação desinteressada da verdade e dos resultados generosos para o progresso humano. [...] Devemos ter cuidado para não produzir o que poderíamos chamar de 'vulgarização científica', o que, longe de reduzir a alienação do homem com relação à ciência e à tecnologia, contribuiria, na realidade, para aumentá-la, fornecendo a ilusão, perigosa, de ter compreendido o princípio sem entrar na essência da atividade da ciência contemporânea: sua complexidade, sua coerência e seu esforço.

Sendo assim, precisamos de uma imagem de ciência e tecnologia que possa trazer à tona a dimensão social do desenvolvimento científico-tecnológico, entendido como produto resultante de fatores culturais, políticos e econômicos. Seu contexto histórico deve ser analisado e considerado como uma realidade cultural que contribui de forma decisiva para mudanças sociais, cujas manifestações se expressam na relação do homem consigo mesmo e os outros.

Para que essas discussões e participações públicas possam se tornar efetivas, é necessário que os cidadãos exijam seus direitos de vez e voz. Deve haver uma igualdade, permitindo a participação direta de todos, e não somente de especialistas ou autoridades públicas. É preciso exigir transparência na transmissão da informação, da disponibilidade de tempo e de meios para participar das discussões, bem como igualdade de tratamento de opiniões. As propostas deverão ter caráter efetivo e ativo, podendo influenciar realmente no assunto em debate, permitindo ao público envolver-se nos problemas e não unicamente na decisão final, que poderia já estar planejada.

As afirmativas anteriores somente serão possíveis se tivermos um público formado na compreensão do funcionamento da tecnociência, percebendo que o debate e a negociação são métodos que permitem a resolução de conflitos que envolvem o interesse da sociedade, podendo contribuir ao desafio de viver em uma sociedade voltada para a democracia.

\footnotetext{
${ }^{4}$ Silogismo utilizado por Ubiratan D' Ambrósio em sua obra 'Da realidade à ação: reflexões sobre a Educação Matemática”, 1986, para expressar idéias tais como religião, valores, filosofias, ideologias e ciência como manifestações do saber, que se incorporam à realidade. [...] São os artefatos e mentefatos que resultam da ação, e que ao se incorporarem à realidade, vêm modificá-la. Aí se situa a tecnologia, como síntese de artefatos e mentefatos.
} 
Segundo nossa avaliação, algumas dessas atitudes já começaram a ser tomadas nesse sentido, envolvendo discussões, questionamentos e críticas em torno do desenvolvimento científico-tecnológico. Uma delas vem ganhando corpo em vários setores da sociedade, sendo nominada pela sigla CTS (Ciência, Tecnologia e Sociedade). Os pressupostos do movimento CTS têm se ampliado em toda sociedade e, principalmente, vêm recebendo cada vez mais adeptos na área educacional.

Esse movimento tem se manifestado desde 1970, tendo sido base para construir currículos em vários países, em especial os de ciências, dando prioridade a uma alfabetização em ciência e tecnologia interligada ao contexto social. Originou-se a partir de correntes de investigação em filosofia e sociologia da ciência. Seu caráter interdisciplinar compreende "[...] uma área de estudos onde a preocupação maior é tratar a ciência e a tecnologia, tendo em vista suas relações, conseqüências e respostas sociais" (BAZZO e COLOMBO, 2001, p. 93). Visa, também, ressaltar a importância social da ciência e da tecnologia, de forma a enfatizar a necessidade de avaliações críticas e análises reflexivas sobre a relação científico-tecnológica e a sociedade. Além dos currículos de ciências, tem abrangido as disciplinas das ciências sociais e humanidades, entre elas a filosofia, história da ciência e economia.

Para melhor explorar esse enfoque na área educacional, utilizaremos, neste artigo, os pressupostos da pesquisa bibliográfica. Dessa forma, ao consultar livros, teses e artigos científicos com suporte na posição de diversos autores que abordam o assunto na educação, procuramos ressaltar a importância do movimento CTS como impulsionador de questionamentos críticos e reflexivos acerca do contexto científico-tecnológico e social e, em especial, destacar sua relevância no Ensino Médio.

\section{CTS e educação}

Desde que se iniciou, há mais de trinta anos, um dos principais campos de investigação e ação social do movimento CTS tem sido o educativo. Nesse campo de investigação, que comumente chamamos de "enfoque CTS no contexto educativo", percebemos que ele traz a necessidade de renovação na estrutura curricular dos conteúdos, de forma a colocar ciência e tecnologia em novas concepções vinculadas ao contexto social. De acordo com Medina e Sanmartín (1990), quando se pretende incluir o enfoque CTS no contexto educacional é importante que alguns objetivos sejam seguidos:

- Questionar as formas herdadas de estudar e atuar sobre a natureza, as quais devem ser constantemente refletidas. Sua legitimação deve ser feita por meio do sistema educativo, pois só assim é possível contextualizar permanentemente os conhecimentos em função das necessidades da sociedade.

- Questionar a distinção convencional entre conhecimento teórico e conhecimento prático - assim como sua distribuição social entre 'os que pensam' e 'os que executam' - que reflete, por sua vez, um sistema educativo dúbio, que diferencia a educação geral da vocacional.

- Combater a segmentação do conhecimento, em todos os níveis de educação.

- Promover uma autêntica democratização do conhecimento científico e tecnológico, de modo que ela não só se difunda, mas que se integre na atividade produtiva das comunidades de maneira crítica. 
Dessa forma, a importância de discutir com os alunos os avanços da ciência e tecnologia, suas causas, conseqüências, os interesses econômicos e políticos, de forma contextualizada, está no fato de que devemos conceber a ciência como fruto da criação humana. Por isso, ela está intimamente ligada à evolução do ser humano, desenvolvendo-se permeada pela ação reflexiva de quem sofre/age as diversas crises inerentes a esse processo de desenvolvimento.

A idéia de levar para sala de aula o debate sobre as relações existentes entre ciência, tecnologia e sociedade - tanto no Ensino Fundamental quanto no Ensino Médio - vem sendo difundida por meio dos Parâmetros Curriculares Nacionais (PCNs) como forma de Educação Tecnológica, a qual não seria voltada para confecção de artefatos, mas para a compreensão da origem e do uso que se faz desses artefatos e também mentefatos na sociedade atual. Para isso, precisamos entender a Educação Tecnológica num sentido que, conforme Palacios et al. (1996), leve os alunos a compreender a dimensão social da ciência e tecnologia, tanto do ponto de vista dos seus antecedentes sociais quanto de suas conseqüências sociais e ambientais. Ou seja, é preciso compreendê-la no que diz respeito aos fatores de natureza social, política ou econômica que modulam a mudança científico-tecnológica e no que concerne às repercussões éticas, ambientais ou culturais dessa mudança.

Verificamos, assim, que a Educação Tecnológica encaminha-se para o enfoque CTS, que vem sendo muito difundido, principalmente no ensino de ciências, acentuando-se a partir de 1980. Em nível internacional impulsionou os periódicos da área de Ensino de Ciências e Matemática a publicarem vários artigos sobre o tema, entre eles destacamos a Revista Science \& Education e International Journal of Science Education, tendo esta última publicado um volume especial - Special issues: Science, Technology and Society (v. 10, n. 4, 1988). Além disso, citamos também a existência da International Organization for Science and Technology Education (IOSTE), que em 2006 realizou seu décimo segundo simpósio internacional, com o intuito de discutir assuntos que envolvem o contexto científico-tecnológico e social.

É importante lembrar que vários trabalhos sobre o tema vêm sendo desenvolvidos há algum tempo dentro de instituições escolares. Cruz (2001) cita, em sua tese, alguns dos mais conhecidos:

- Nos Estados Unidos: Chemistry and Community da Amerian Chemical Society; Chautanqua Program de Iowa; Projeto 2061, da American Association for the Advancement of Science; Projeto Scope, Sequence and Coordination da International Assessment of Education Progress.

- Na Europa: SATIS (Science And Technology In Society) e SISCON (Science In a Social Context), na Inglaterra.

De acordo com Cerezo et al. (2003), além dos trabalhos já citados, duas associações merecem destaque por suas pesquisas nessa área: National Science Teachers Association (Norteamericana) e Association for Science Education (Britânica).

Entre outros autores que vêm escrevendo sobre o movimento CTS e ressaltando sua importância para a educação, na Espanha estão Palácios et al. (1996), Sanz et al. (1996), Tortajada e Peláez. (1997), Acevedo (2001), Acevedo et al. (2004) e Cerezo et al. (2003). De acordo com Cerezo (2002), o Ministério de Educação e Cultura espanhol introduziu CTS como disciplina optativa em todos os cursos de graduação para alunos entre 16 e 18 anos (Lei de Ordenamento Geral do Sistema Educacional) e, no ensino secundário, obrigatória como complemento transversal de disciplinas de ciências para alunos entre 14 e 16 anos (Ensino Superior 
Obrigatório). Isso fez com que vários professores do ensino secundário e universitário buscassem aperfeiçoamento.

Na Espanha, a disciplina de CTS consta de cinco blocos temáticos, que abrangem: perspectiva histórica sobre ciência, tecnologia e sociedade; sistema tecnológico; repercussões sociais do desenvolvimento científico e tecnológico; controle social da atividade científica e tecnológica; desenvolvimento científico-tecnológico: reflexões filosóficas. A Espanha conta, também, com a revista Enseñanza de Las Ciencias que, entre outros periódicos, procura trazer artigos que enfoquem tal preocupação.

Osorio (2002) cita a relevância de alguns seminários apresentados em universidades, os quais podem retratar a importância do movimento para os países latinos. Entre eles, encontramos: Seminário do Programa Universitário de Investigação - PUI - Ciência, Tecnologia e Cultura, Universidade Nacional de Bogotá; Seminário de História da Biologia, Universidade Nacional de Medellín; Seminário de História das Matemáticas, Universidade do Valle em Cali; Seminário de História da Medicina, Universidade do Bosque de Bogotá. Outras experiências realizadas na Universidade Tecnológica de Pereira e na Universidade de Antioquia, em Medellín, também merecem ser destacadas, em termos do enfoque CTS.

Voltando o foco para o Brasil, os trabalhos sob a perspectiva CTS podem ser encontrados em periódicos da área de Ensino de Ciências e Matemática como, por exemplo, Revista Ensaio - Pesquisa em Educação em Ciências e Revista Ciência \& Educação, entre outras. Alguns são também encontrados em livros, teses e dissertações e, entre outros, destacamos: Bazzo (1998); Auler, (2002); Mion et al. (2001); Leal e Gouvêa (2001); Cruz (2001); Bazzo e Colombo (2001); Mortimer e Santos (2000); Koepsel (2003); Pinheiro e Bazzo (2004); Pinheiro (2005).

Além dessas, há outras bibliografias que trazem relatos de experiências, pesquisa teórica, experimentos práticos, entre outros assuntos pertinentes. Uma boa indicação de consulta é o site da Organização dos Estados Iberoamericanos, OEI (<www.campus-oei.org>), que, além de oferecer um campo diversificado da literatura, disponibiliza a revista eletrônica Iberoamericana de Educación - Enseñanz̧a de la tecnología, que traz vários artigos direcionados para a área CTS, principalmente voltados para o campo educacional.

Ao analisarmos os referenciais bibliográficos até aqui citados, percebemos que as pesquisas e experiências voltadas para o enfoque CTS na educação concentram-se em trabalhos que, de acordo com Walks (1990) e Medina e Sanmartín (1990), podem ser classificados em três modalidades: introdução de CTS nos conteúdos das disciplinas de ciências (enxerto CTS); a ciência vista por meio de CTS; e CTS puro. De acordo com Palacios et al. (1996), pode-se resumir os objetivos dessas três modalidades da seguinte forma:

- Enxerto CTS: introdução de temas CTS nas disciplinas de ciências, abrindo discussões e questionamentos do que seja ciência e tecnologia. Nos Estados Unidos o projeto Harvard Project Physics e, na Europa, o projeto SATIS (Science and Tecbnology in Society) englobam essa modalidade.

- Ciência e tecnologia por meio de CTS: estrutura-se o conteúdo científico por meio do CTS. Essa estruturação pode acontecer numa só disciplina ou por meio de trabalhos multidisciplinares e interdisciplinares. Podemos ver essa forma de trabalho no PLON (Dutch physics curriculum development project), desenvolvido na Holanda.

- CTS puro: ensina-se ciência, tecnologia e sociedade por intermédio do CTS, no qual 
o conteúdo científico tem papel subordinado. O projeto mais conhecido nessa modalidade é o SISCON (Studies in a Social Context), na Inglaterra.

Nas três categorias, o professor é o grande articulador para garantir a mobilização dos saberes, o desenvolvimento do processo e a realização de projetos, nos quais os alunos estabelecem conexões entre o conhecimento adquirido e o pretendido com a finalidade de resolver situações-problema, em consonância com suas condições intelectuais, emocionais e contextuais.

Cabe ressaltar que o enfoque CTS que venha a ser inserido nos currículos é apenas um despertar inicial no aluno, com o intuito de que ele possa vir a assumir essa postura questionadora e crítica num futuro próximo. Isso implica dizer que a aplicação da postura CTS ocorre não somente dentro da escola, mas, também, extra-muros. De acordo com Osório (2002, p. 64):

O enfoque educativo em CTS tanto recupera os espaços críticos dessa relação conjunta ao desenvolver as implicações e os fins do desenvolvimento científicotecnológico em um emaranhado social, político e ambiental, quanto se nos apresenta como um campo de análises propício para entender e educar o fenômeno tecnocientífico moderno. (Tradução nossa)

Nesse encaminhamento, o ensino-aprendizagem passará a ser entendido como a possibilidade de despertar no aluno a curiosidade, o espírito investigador, questionador e transformador da realidade. Emerge daí a necessidade de buscar elementos para a resolução de problemas que fazem parte do cotidiano do aluno, ampliando-se esse conhecimento para utilizá-lo nas soluções dos problemas coletivos de sua comunidade e sociedade.

Com o enfoque CTS, o trabalho em sala de aula passa a ter outra conotação. A pedagogia não é mais um instrumento de controle do professor sobre o aluno. Professores e alunos passam a descobrir, a pesquisar juntos, a construir e/ou produzir o conhecimento científico, que deixa de ser considerado algo sagrado e inviolável. Ao contrário, está sujeito a críticas e a reformulações, como mostra a própria história de sua produção. Dessa forma, aluno e professor reconstróem a estrutura do conhecimento. Em nível de prática pedagógica, isso significa romper com a concepção tradicional que predomina na escola e promover uma nova forma de entender a produção do saber. É desmitificar o espírito da neutralidade da ciência e da tecnologia e encarar a responsabilidade política das mesmas. Isso supera a mera repetição do ensino das leis que regem o fenômeno e possibilita refletir sobre o uso político e social que se faz desse saber. Os alunos recebem subsídios para questionar, desenvolver a imaginação e a fantasia, abandonando o estado de subserviência diante do professor e do conhecimento apresentado em sala de aula.

\section{O enfoque CTS e o Ensino Médio}

Ao se propor uma reestruturação nas leis que regem o contexto educacional, bem como o estabelecimento de suas diretrizes curriculares, muito se tem a caminhar para que as propostas se efetivem. É necessário que saibamos interpretar o que cada um dos objetivos 
pretende e as possíveis direções para atingi-los. Acreditamos ser interessante tecer, neste momento, alguns comentários referentes aos objetivos do Ensino Médio e, por conseqüência, às propostas dos Parâmetros Curriculares Nacionais do Ensino Médio (PCNEMs), por serem de grande importância para o contexto social, bem como destacar algumas possíveis maneiras de avançar em direção à concretização desses objetivos.

O primeiro destaque que fazemos relaciona-se a um dos objetivos estabelecidos nos PCNEMs:

A formação da pessoa, de maneira a desenvolver valores e competências necessárias à integração de seu projeto individual ao projeto da sociedade em que se situa; o aprimoramento do educando como pessoa humana, incluindo a formação ética e o desenvolvimento da autonomia intelectual e do pensamento crítico; a preparação e orientação básica para a sua integração ao mundo do trabalho, com as competências que garantam seu aprimoramento profissional e permitam acompanhar as mudanças que caracterizam a produção no nosso tempo; o desenvolvimento das competências para continuar aprendendo, de forma autônoma e crítica, em níveis mais complexos de estudos. (BRASIL, 1999, p. 23)

Percebemos que uma das preocupações no Ensino Médio é em relação à função social desse grau de ensino. É possível verificar que ela está vinculada à formação do indivíduo em sociedade, enquanto cidadão. Isso significa dizer que, ao consultarmos o contexto histórico ${ }^{5}$ dos objetivos que o Ensino Médio assumiu até chegar aos dias atuais, percebemos que sua prioridade deixou de ser a preparação para o ensino superior ou a formação profissionalizante. A preocupação agora é pautada em um currículo que

[...] promova no indivíduo, tanto em termos de desenvolvimento pessoal, quanto em termos do desenvolvimento social, quando ele poderá questionar e posicionarse, por exemplo, quanto à hegemonia das nações que detêm o poder do conhecimento científico-tecnológico. (GRINSPUN, 1999, p. 28).

Para que isso venha a ocorrer, os PCNEMs reafirmam a necessidade de um "[...] fortalecimento dos laços de solidariedade e de tolerância recíproca; formação de valores; aprimoramento como pessoa humana; formação ética; exercício da cidadania". (BRASIL, 1999, p. 161).

Nesse sentido, aparece explícito no contexto da Lei de Diretrizes e Bases da Educação Nacional (LDB), que a sociedade moderna exigirá do cidadão muito mais do que saber ler, escrever e contar. Assim, propõe-se que para o aluno acompanhar os níveis de desenvolvimento da sociedade, em seus vários setores, precisará ter conhecimentos relacionados à estética da sensibilidade, que valoriza o lado criativo e favorece o trabalho autônomo; a política da igualdade,

${ }^{5}$ Para entender o contexto histórico pesquisamos diversas obras na área de Educação entre elas: Pilletti (1988), Ribeiro (1991) e Romanelli (1989). 
que busca solidariedade e respeita a diversidade, como base para a cidadania; e a ética da identidade, que promove a autonomia do educando, da escola e das propostas pedagógicas. A educação deverá contribuir para a auto-formação do aluno, estimulando-o a assumir a condição humana, incentivando-o a viver de forma a se tornar um cidadão, que numa democracia, será definido por sua solidariedade e responsabilidade.

Todos esses saberes são necessários para que o educando possa viver numa sociedade moderna e tecnológica como a nossa. Logo, é necessário que tais saberes voltem-se, também, para a compreensão da ciência e da tecnologia, que se tornam presença contínua em nosso meio. Por esse motivo, a LDB ressalta, em seu artigo 36, que o Ensino Médio “[...] destacará a educação tecnológica, a compreensão do significado da ciência, das letras e das artes; o processo histórico de transformação da sociedade e da cultura; a língua portuguesa como instrumento de comunicação, acesso ao conhecimento e exercício da cidadania". O artigo afirma que, além de ter acesso aos conhecimentos relacionados à ciência e à tecnologia, o educando precisará entender como esses processos se formaram, em que eles implicam, quais suas conseqüências e que tipo de atitudes o cidadão deverá ter diante dos problemas. É necessário que ele possa efetivar sua participação enquanto ente de uma comunidade, buscando informações, aquelas diretamente vinculadas aos problemas sociais que afetam o cidadão e seu meio, exigindo um posicionamento quanto ao encaminhamento de soluções.

Para formar um cidadão com essas compreensões, é preciso que o Ensino Médio dê ao aluno condições de compreender a natureza do contexto científico-tecnológico e seu papel na sociedade. Isso implica adquirir conhecimentos básicos sobre filosofia e história da ciência, para estar a par das potencialidades e limitações do conhecimento científico pois, para que o cidadão possa tomar suas decisões, precisa ter evidências e fundamento.

Para que essas colocações se efetivem, o artigo 36 ainda complementa que novas formas de trabalho em sala de aula deverão ser propostas, pois fazem-se necessárias metodologias de ensino e de avaliação que estimulem a iniciativa dos estudantes. Dessa forma, caso persista o processo ensino-aprendizagem atual, não será formado um cidadão dotado das habilidades que o Ensino Médio pretende. Urge pensar em novas formas de trabalho, de metodologia, de enfoque e de posturas. É preciso estimular o aluno a desenvolver a adaptabilidade e flexibilidade, formando-o como pessoa que tome decisões, avalie o papel das decisões humanas na determinação da sobrevivência e da vida na sociedade futura. É, pois, imprescindível desenvolver nos alunos a capacidade de diferenciar o que é conhecimento do que é informação, verificando o que há de mais relevante para poder resolver criticamente um problema específico no campo sócio-tecnológico.

Os PCNEMs expressam que não é necessário criar novas disciplinas ou saberes. No entanto, é importante utilizar os conhecimentos de várias disciplinas para resolver um problema concreto ou compreender determinado fenômeno por meio de diferentes pontos de vista. A proposta de estabelecer as três áreas de ensino (Linguagens, Códigos e suas Tecnologias; Ciências da Natureza, Matemática e suas Tecnologias e Ciências Humanas e suas Tecnologias) foi o primeiro passo no sentido de reunir conhecimentos correlatos e trabalhar em conjunto. Tal idéia visa desfragmentar os conhecimentos, colocando-os em áreas, de forma a incentivar os professores a reunir os saberes, criando projetos, renovando a prática pedagógica visando novos rumos. De acordo com Morin (2003), os problemas mais graves que devem ser revistos no ensino são: a compartimentalização dos saberes e a incapacidade de articulá-los uns aos 
outros, uma vez que a aptidão para contextualizar e integrar é qualidade fundamental da mente humana e precisa ser desenvolvida e não atrofiada.

Nesse sentido, Morin (2003, p. 102) complementa que na direção da desfragmentação dos saberes é necessário refletir sobre alguns pontos essenciais na missão de ensinar:

Fornecer uma cultura que permita distinguir, contextualizar, globalizar os problemas multidimensionais, globais e fundamentais, e dedicar-se a eles; preparar as mentes para responder aos desafios que a crescente complexidade dos problemas impõe ao conhecimento humano; preparar mentes para enfrentar as incertezas que não param de aumentar, levando-as não somente a descobrirem a história incerta e aleatória do universo, da vida, da humanidade, mas também promovendo nelas a inteligência estratégica e a aposta em um mundo melhor.

Assim, o ensino que se pretende é aquele que propicie condições para o desenvolvimento de habilidades, o que não se dá simplesmente por meio do conhecimento, mas de estratégias de ensino muito bem estruturadas e organizadas. As propostas para o ensino do cidadão precisam levar em conta os conhecimentos prévios dos alunos, o que pode ser feito mediante a contextualização dos temas sociais, na qual se solicita a opinião dos alunos a respeito do problema que o tema apresenta, mesmo antes de ser discutido do ponto de vista do conhecimento (Matemática, Física, Química, Biologia etc). Trabalhar com os alunos nesse sentido não se restringe a uma simples adequação de fatos descontextualizados da realidade, mas implica a redefinição de temas sociais próprios ao contexto nacional, local, ou adaptados à problemática brasileira. Para que a reforma do ensino possa se concretizar, conforme argumenta Morin (2003), deve-se promover uma reforma do pensamento. Só assim ocorrerá a reforma do ensino.

Nesse sentido, entendemos que os objetivos propostos na LDB e configurados nos PCNEMs encontram aplicações no enfoque CTS pois, como a proposta para o Ensino Médio foi estabelecida, percebe-se a relevância em aproximar o aluno da interação com a ciência, a tecnologia e com todas as dimensões da sociedade. Assim, consideram-se suas relações recíprocas, oportunizando ao educando uma concepção ampla e social do contexto científicotecnológico. Nesse processo, a relação educando/sujeito deixa seu status de cognoscente, que se relaciona com objetos, e passa a estabelecer novas relações intersubjetivas para a construção de um entendimento e, por conseguinte, de um conhecimento científico, que inclui a reação, reelaborando-o, ampliando-o, criando possibilidades de ação.

Porém, não basta apenas julgarmos importantes os pressupostos do enfoque CTS e sua conseqüente relevância para o contexto educacional. Segundo Santos e Mortimer (2000), antes, ao ter em mente a introdução do enfoque CTS em sala de aula, em particular no Ensino Médio, precisamos considerar alguns pontos. Um deles é a utilização dos modelos curriculares de outros países. Comentam os autores que muitas vezes esses modelos são transferidos para nossa realidade sem a devida contextualização local, ou seja, sem considerar as necessidades de cada realidade, os problemas existentes, a ciência e tecnologia advinda de cada país. Outro problema enfrentado é a formação de professores. Essa necessidade é reforçada por autores como: Medina e Sanmartín (1990); Rubba e Harkness (1993); Rubba et al. (1996); Acevedo (2001); Osório (2002), Auler (2002) e Acevedo et al. (2004), que realizaram pesquisas sobre 
CTS com professores de diversos níveis. Tais estudos mostraram o pouco conhecimento dos professores em relação à abordagem CTS, evidenciando a necessidade de uma formação específica neste campo, isto é, a necessidade de temas CTS serem incluídos na formação inicial e continuada dos professores, para que estes possam contribuir mais adequadamente para melhorar e inovar o ensino das ciências, visando conseguir uma alfabetização científica e tecnológica mais ajustadas às suas necessidades.

São poucas as instituições no Brasil que têm linha de pesquisa voltada para o enfoque CTS, o que faz com que a grande maioria de professores não tenha acesso a esse tipo de trabalho. A formação disciplinar também é um problema que não condiz com a necessidade interdisciplinar do enfoque CTS. Nem nossos docentes nem nossos alunos foram - ou estão sendo - formados dentro da perspectiva da interdisciplinaridade, o que torna os objetivos do enfoque CTS algo que exige bastante reflexão antes que se possa agir.

Torna-se, pois, urgente dar subsídios para que os professores de todos os níveis possam refletir sobre os conhecimentos com os quais trabalham, como também sobre o ensinoaprendizagem desses conhecimentos. Assim será possível investir em reformas curriculares que propiciem uma reflexão sobre meta, pontos de vista que unam natureza e cultura, homem e cosmo, e edifiquem uma aprendizagem cidadã capaz de repor a dignidade da condição humana. Não se pode esquecer que as mudanças também requerem uma formação continuada dos docentes, não bastando apenas reformular os currículos das licenciaturas.

Dessa forma, é imprescindível organizar programas de desenvolvimento profissional em serviço dos docentes. Isso equivale dizer que reformas educacionais não dependem somente do desejo dos docentes: é preciso que todas as instâncias educacionais se unam: governo federal, estadual, municipal, escola, funcionários e professores em prol da mesma causa.

\section{Considerações finais}

Diante dos comentários tecidos podemos verificar que os pressupostos do enfoque CTS se interceptam em vários pontos com os objetivos propostos na LDB. Ao conceber o currículo como uma organização conceitual com uma preocupação em temas sociais, procurando desenvolver atitudes que favoreçam o julgamento, mediante o estudo da ciência voltado aos interesses sociais, buscando a compreensão das implicações sociais dos conhecimentos científico e tecnológico, a LDB entra em sintonia com o enfoque CTS.

O caráter interdisciplinar destacado na proposta da LDB configura-se no enfoque CTS, o qual enfatiza a quebra de fronteiras rígidas e excludentes entre os saberes. A busca de um ensino mais reflexivo e contextualizado está em sintonia com esse enfoque, que persegue também os objetivos de formar um cidadão crítico, capaz de interagir com a sociedade.

Contudo, a utilização do enfoque CTS no Ensino Médio não se reduz somente a mudanças organizativas e de conteúdo curricular: alcança, também, a metodologia educativa. Ele parte do princípio no qual o objetivo do professor é promover uma atitude criativa e crítica, ao invés de conceber o ensino como um processo de transmissão de informações por meio de "macetes" e de memorização. Para que se atinja este tipo de formação, será necessária uma nova postura perante os conteúdos a serem estudados, afinal, a pretensão do ensino CTS é buscar e incentivar a participação dos estudantes e minimizar a participação do professor. 
As formas de se trabalhar com o enfoque CTS no Ensino Médio são várias e, principalmente, encontram respaldo em diversos objetivos, tanto da LDB quanto dos PCNEMs, basta que cada um analise os conhecimentos com os quais trabalha em sala de aula e encontre as possibilidades de trilhar esse caminho.

Diante disso, ainda é importante lembrar que para um trabalho em sala de aula encontrar respaldo no enfoque CTS é preciso resgatar as concepções que esse enfoque defende. É necessário entender o intuito para o qual ele surgiu, as necessidades que busca atender, bem como as direções que se propõe a tomar.

Nesse sentido, acreditamos que abrem-se várias perspectivas com a utilização do enfoque CTS. Devido aos objetivos e às propostas de estratégias que apresenta, ele poderá contribuir no questionamento e na crítica, também, de outros conhecimentos, pois não é somente o ensino das ciências ligadas à natureza que deve se responsabilizar pelos princípios de ação cidadã. O ensino da Geografia, História, Matemática, entre outras, também deve se preocupar em desenvolver seu lado reflexivo em favor de um contexto social mais justo.

Precisamos ultrapassar a velha idéia de que discutir sobre ciência é tarefa das disciplinas de química, física ou biologia: participamos de um compromisso social comum. Todos os conhecimentos contribuem em igual escala nas tarefas de lutar por um mundo mais justo e mais humano. Assim, trabalhar dentro de uma determinada disciplina, utilizando-se do enfoque CTS, implica capacitar o educando a participar do processo democrático de tomada de decisões, promovendo a ação cidadã encaminhada à solução de problemas relacionados à sociedade na qual ele está inserido.

Acreditamos que a introdução do enfoque CTS no Ensino Médio poderá promover um ensino-aprendizagem que propicie ao aluno habilidade de discussão sobre assuntos relacionados com a ciência, a tecnologia e a implicação social das ciências nos aspectos ligados à sua área de atuação que possa levá-lo, enfim, a uma autonomia profissional crítica.

\section{Referências}

ACEVEDO, J. A. D. A. La formación del profesorado de enseñanza secundarias para la educación CTS: una cuestión problemática. Disponível em: <http://www.campusoei.org/salactsi/acevedo9.htm>. Acesso em: 10 set. 2001.

.; ALONSO, Á. V.; MASSANERO, M. A. Progresos en la evaluación de actitudes relacionadas con la ciencia mediante el cuestionario de opiniones CTS. Disponível em: < http://www.campus-oei.org/salactsi/acevedo.htm>. Acesso em: 04 out. 2004.

AULER, D. Interações entre Ciência-Tecnologia-Sociedade no contexto da formação de professores de ciências. Florianópolis, 2002. Tese (Doutorado em Educação: Ensino de Ciências) - Universidade Federal de Santa Catarina. 
Ciência, Tecnologia e Sociedade...

BAZZO, W. A. Ciência, Tecnologia e Sociedade: e o contexto da educação tecnológica. Florianópolis: Ed. da UFSC, 1998.

.; COLOMBO, C. R. Educação tecnológica contextualizada: ferramenta essencial para o desenvolvimento social brasileiro. Revista de Ensino de Engenharia, Florianópolis, v. 20, n. 1, p. 9-16, 2001.

BRASIL. Ministério da Educação. Secretaria de Educação Média e Tecnológica.

Parâmetros Curriculares Nacionais do Ensino Médio: bases legais/ Ministério da Educação - Brasília: Ministério da Educação/Secretaria de Educação Médio e Tecnológica, 1999.

CEREZO, J. A. L. Ciência, Tecnologia e Sociedade: o estado da arte na Europa e nos Estados Unidos. In: SANTOS, L. W. (Org.). Ciência, tecnologia e sociedade: o desafio da interação. Londrina: IAPAR, 2002. p. 3-38.

.; LUJÁN, J. L.; GORDILLO, M. M.; et al. Introdução aos estudos CTS (Ciência, Tecnologia e Sociedade). Madrid: OEI, 2003.

CRUZ, S. M. S. C. S. Aprendizagem centrada em eventos: uma experiência com enfoque Ciência, Tecnologia e Sociedade no Ensino Fundamental. Florianópolis, 2001. Tese (Doutorado em Educação) - Centro de Educação, Universidade Federal de Santa Catarina.

D’ AMBRÓSIO, U. Da realidade à ação: reflexões sobre a educação matemática. São Paulo: Summus, 1986.

GRINSPUN, M. P. S. Educação tecnológica. In: GRINSPUN, M. P. S. (Org.). Educação tecnológica: desafios e perspectivas. São Paulo: Cortez, 1999. p. 25-73.

KOEPSEL, R. CTS no Ensino Médio: aproximando a escola da sociedade. Florianópolis, 2003. Dissertação (Mestrado em Educação) - Universidade Federal de Santa Catarina.

LEAL, M. C. E; GOUVÊA, G. Uma visão comparada do ensino em ciência, tecnologia e sociedade na escola e em um museu de ciência. Ciência \& Educação, Bauru, v. 7, n. 1, p. 67-84, 2001.

MEDINA, M.; SANMARTÍN, J. El programa Tecnología, Ciencia, Natureza y Sociedad. In: Ciencia, Tecnología y Sociedad: estudos interdisciplinares en la universidad, en la educación y en la gestión pública. Barcelona: Anthropos, 1990. p. 114-121.

MION, R.; ANGOTTT, J. A.; BASTOS, F. P. Educação em Física: discutindo Ciência, Tecnologia e Sociedade. Ciência \& Educação, Bauru, v. 7, n. 2, p. 183-197, 2001.

MORIN, E. A cabeça bem feita: repensar a reforma, reformar o pensamento. 8. ed. Rio de Janeiro: Bertrand Brasil, 2003.

MORTIMER, E. F.; SANTOS, W. L. P. Uma análise de pressupostos teóricos da abordagem C-T-S (Ciência-Tecnologia-Sociedade) no contexto da educação brasileira. Ensaio Pesquisa em Educação em Ciências, Belo Horizonte, v. 2, n. 2, p. 133-162, 2000. 
Pinheiro, N. A. M. et al.

OSORIO, C. O. M. La educación científica y tecnológica desde el enfoque en Ciencia, Tecnología y Sociedad: aproximaciones y experiencias para la educación secundaria. Revista Ibero-Americana de Educação, Madrid, n. 28, p. 61-81, 2002.

PALACIOS, F. A.; OTERO, G. F.; GÁRCIA, T. R. Ciencia, Tecnología y Sociedad. Madrid: Ediciones Del Laberinto, 1996.

PILLETTT, N. Ensino de $2^{\circ}$. grau: educação geral ou profissionalizante. São Paulo: EPU, 1988.

PINHEIRO, N. A. M.; BAZZO, W. A.Educação crítico-reflexiva para um Ensino Médio científico tecnológico: a contribuição do enfoque CTS para o ensinoaprendizagem do conhecimento matemático. Florianópolis, 2005. Tese (Doutorado em Educação Científica e Tecnológica) - Universidade Federal de Santa Catarina.

; __ Uma experiência matemática sob o enfoque CTS: subsídios para discussões. Revista Perspectiva, Erechim, v. 28, p.33-49, 2004.

RIBEIRO, M. L. S. História da educação brasileira: a organização escolar. São Paulo: Cortez, 1991.

ROMANELLI, O. O. História da educação no Brasil (1930-1973). Petrópolis: Vozes, 1989.

RUBBA, P. A.; HARKNESS, W. L. Examination of preservice and in-service secondary science teachers' beliefs about science-technology-society interactions. Science Education, v. 77, n. 4, p. 407-431, 1993.

.; SCHONEWEG, C.; HARKNESS, W. L. A new scoring procedure for the views on Science- Technology-Society instrument. International Journal of Science Education, London, v. 18, n. 4, p. 387-400, 1996.

SANZ, M. A.; MORTALLA, T. D.; GÓMEZ, Y. H.; et al. Ciencia, Tecnología y

Sociedad. Madrid: Noesis, 1996.

TORTAjADA, J. F. T.; PELÁEZ, A. L. Ciencia, Tecnología y Sociedad. Madrid: Sistema, 1997.

WALKS, L. Educación en ciencia, tecnología y sociedad: orígenes, desarrollos internacionales y desafíos intelectuales. In: MEDINA, M.; SANMARTIN, J. (Orgs.). Ciencia, tecnología y sociedad, estudios interdisciplinares en la universidad, en la educación y en la gestión pública. Barcelona: Anthropos, 1990. p. 42-75.

Artigo recebido em setembro de 2006 e aceito em janeiro de 2007. 